\title{
Article \\ The Impact of COVID-19 on Learning: Investigating EFL Learners' Engagement in Online Courses in Saudi Arabia
}

\author{
Iman Oraif $1, *$ and Tariq Elyas $2, *$ (1) \\ 1 Department of English Language and Literature, College of Languages and Translation, \\ Al-Imam Muhammad Ibn Saud Islamic University, Riyadh 3204, Saudi Arabia \\ 2 Department of European Languages and Literature, Faculty of Arts and Humanities, \\ King Abdulaziz University, Jeddah 21589, Saudi Arabia \\ * Correspondence: IMOraif@imamu.edu.sa (I.O.); telyas@kau.edu.sa (T.E.)
}

check for updates

Citation: Oraif, I.; Elyas, T. The Impact of COVID-19 on Learning: Investigating EFL Learners' Engagement in Online Courses in Saudi Arabia. Educ. Sci. 2021, 11, 99. https://doi.org/10.3390/

educsci11030099

Academic Editor: Palitha Edirisingha

Received: 22 January 2021

Accepted: 22 February 2021

Published: 2 March 2021

Publisher's Note: MDPI stays neutral with regard to jurisdictional claims in published maps and institutional affiliations.

Copyright: (c) 2021 by the authors. Licensee MDPI, Basel, Switzerland. This article is an open access article distributed under the terms and conditions of the Creative Commons Attribution (CC BY) license (https:// creativecommons.org/licenses/by/ $4.0 /)$.

\begin{abstract}
As a result of the COVID-19 pandemic, most learning around the world has been transferred online. Learners who previously engaged in traditional learning now face a new challenge, a distinctive rise in e-learning. This drastic change could impact their learning behavior and acceptance of the change. As a result, their learning engagement could be affected massively. The present study therefore explores learners' level of engagement in online courses using a designated school platform within the context of Saudi Arabia. A reliable measure was implemented in the study based on the Student Course Engagement Questionnaire (SCEQ). A survey was consequently conducted in a high school in Saudi Arabia, with a sample of 379 female English as a foreign language (EFL) learners studying a general English language course. The results revealed a high level of engagement among EFL Saudi learners. This helped to generate recommendations to improve EFL practices, primarily through the use of an online environment either at the national level in the Saudi context or the international level.
\end{abstract}

Keywords: COVID-19; EFL learners; engagement; student course engagement questionnaire; Madrasti; platform; online learning

\section{Introduction}

COVID-19 has resulted in schools being closed all across the world. Globally, over 1.2 billion students between elementary up to university level are off school [1]). While countries are at different points in their COVID-19 infection rates, there are currently more than 186 countries affected by school closure due to the pandemic [1]. Therefore, as a result of COVID-19, education has changed dramatically, with a distinctive rise in e-learning, whereby teaching is undertaken remotely or virtually and on digital platforms. The closure of all educational institutions in Saudi Arabia, due to the COVID-19 outbreak, has caused an unplanned rapid shift from the customary 'traditional' learning approach [2] to the new government-endorsed approach, namely, online learning. Saati claims that 'without the outbreak of the pandemic, our schools and universities would not have practiced distance learning in such a fluent way' [3]. The Saudi government has ensured that all sectors work together in a network, cooperating to prevent the spread of COVID-19. Thus, closure across all educational sectors in Saudi Arabia was decided by the Ministry of Education (MoE), on the recommendation of the Ministry of Health $(\mathrm{MoH})$. According to Elyas, regarding the current educational shift the Ministry of Education was in a dilemma. However, remarkably they managed to control the situation by introducing the new official way of learning and creative way of online learning [4]. The first step towards this significant shift has been to design a platform to ensure continuity in learning.

Since the beginning of the period of school suspension in Saudi Arabia, the MoE has worked hard to efficiently adapt the educational system to distance learning. In fact, distance learning is not new to Saudi Arabia [5]; since community colleges and open 
universities were first established in the Kingdom in 2002 [5]. For example, King Abdulaziz University adopted a home study system 30 years ago, which only required physical attendance of final exams. This was deemed to be a form of online/distance learning. In light of the current status of distance learning in Saudi Arabia, and in consideration of these efforts, learners could display a negative attitude and resist the change. For example, they could find the learning experience challenging and consider that it failed to meet their needs. Thus, they might not engage with the course. Building on Handelsman et al. definition of engagement and focusing on the micro-level of 'what happens in and immediately surrounding class' [6] (p. 185), the present study attempts to answer the following questions:

1. What is the level of engagement in English classes among high school EFL learners when online learning is adopted?

2. How do EFL learners feel towards receiving instruction in English classes in an online environment?

\section{Literature Review}

\subsection{The Technological Shift}

Many aspects of life, including education, have entered a 'new phase'. This is because of the impact of technology on communication, which converts it to a digital form. Technology has altered human interaction through the adoption of virtual worlds, which provide such advantages as enabling people to get to know each other or communicate without having to travel' [7]. It also implies that classrooms have the potential to become dynamic virtual worlds. Such dynamism is due to the non-restrictive aspects of these virtual worlds that can be easily modified and adopted based on the needs for learners. People from different cities and regions can also conveniently converge inside a virtual space, allowing for unique and very diverse classrooms within one country or even a multiple countries. With the spread of COVID-19, people have become physically 'distant', but have also become digitally 'close' in many cases. This increased engagement could be regarded as an opportunity to translate physical aspects of life into a digital dimension. During the pandemic, Kantar reported that social media engagement had increased by $61 \%$ over normal usage rates [8] (paragraph. 2).

Particularly with education, the digital world has the potential to transform the classroom with its accessibility, vastness, expansive digital environs, and ability to interact with classmates/instructors from different countries. Digital education or remote learning may therefore be described as open. Collectif de Chasseneuil defines this openness as:

[A]n organized and targeted educational environment which takes account of the learner's uniqueness in [ ... ] his or her individual and collective dimensions supported by complementary learning situations in terms of places, timing, educational resources, human and technological mediations [9] (p. 185).

This openness in the digital world could make education increasingly accessible, enabling it to be tailored to individual needs. The way that each person accesses content is different and therefore, the acquisition of information should also be possible using different methods, whether through video, audio, text or another medium. The individuals choose what suits them according to their needs, which also affects how the acquired information is manifested to illustrate the knowledge gained. Learners can create various types of content from what they have learned, using videos, images or text, provided that they have the suitable means [10] (for more information about COVID-19).

\subsection{Covid-19 and Education in the Saudi Context}

This new remote form of education has its own culture, ideologies and mechanisms, which might not be familiar to all, regardless of whether they are teaching staff, students, or members of students' families [11]. Accordingly, this 'sudden shift from regular traditional classes to online classes [has presented students and teachers with] massive challenges [12]. 
Consequently, they have raised several issues such as problems with various online teaching platforms, a lack of prior experience in using these platforms, poor Internet connectivity, etc. [12]. Hamad bin Mohammed al-Sheikh, the Saudi Minister of Education, has declared that Saudi Arabia first began providing distance education services years ago, but the systems were recently upgraded in response to the coronavirus pandemic [13]. Since the beginning of this shift, the MoE has introduced several learning strategies to facilitate distance learning for students. For example, the Ministry has applied mechanisms and solutions for distance learning; established the' Ien (عين) TV Channel', a 'Ien YouTube Channel', a 'Ien Virtual Gate', and other electronic platforms to provide eight million teaching hours, three million items of digital content, and three and a half million virtual classrooms [13]. Ziaul Hoq also mentions that the MoE is transmitting educational content for all grades via $\mathrm{TV}$, as well as via social media networks, while nominating around 127 teachers and administrators to offer regular teaching in 112 enlightening courses across several TV channels (transmitting nationwide from a classroom in Riyadh) [14].

By the beginning of the current academic year in 2020, the MoE was ready to launch the new Madrasati platform. This ('My School' (Madrasati) platform is a new platform created during the COVID-19 in Saudi Arabia that serves over six million male and female students and their parents, and 525,000 people in education posts. The platform has various features such as visual communication; and uploading assignments, enrichment materials, recorded lessons, tests, and examinations, among others) (see Appendix A, Figure A1). In addition, there are $23 \mathrm{TV}$ channels with a specific channel for each level. This would complement what had been prepared for the benefit of each student such as 'Future Gate', 'the Saudi Virtual School', and the 'Virtual Kindergarten' [13,14]. The MoE has implemented numerous educational policies to enable students to maximize these electronic and educational possibilities effectively. Thus, morning hours are assigned to intermediate and secondary school students, and afternoon hours are assigned to elementary school students, so that parents can follow up with their children to help them with their distance online learning in the evening.

Al-Mayman points out that the MoE is working closely with other ministries to ensure that each student has the necessary tools and resources to efficiently complete the school year via distance learning. The aim is to broadcast during school time to accommodate students who lack Internet access, or who have no devices to access the platform [13]. Even though as many as six million students and half a million teachers across Saudi Arabia have registered to join daily virtual classes on the new Madrasati platform, many students have their own financial burdens, to the extent that they cannot afford to buy computers or pay for stable Internet access. Commenting on the Ministry's pledge that students who cannot afford computers will not be left behind, 'there are a number of initiatives and collaborations between the ministry and other organizations such as Takaful to help students who cannot afford the basic equipment to access the platform' [14]). Takaful which is a charity foundation established to support financially disadvantaged students in Saudi public schools to continue and succeed in receiving proper education. The enterprise system and regulations of Takaful were approved in 2010 and it was officially registered in the Ministry of Social Affairs. Takaful receives generous support from The Custodian of the Two Holy Mosques which is around half a billion Saudi Riyal per year. Moreover, the MoE has been successful in providing six outstanding educational platforms, through which three million students have already benefitted. Equally, some educational television channels have received 61 million views, while the Ien national educational gateway offers 45,000 courses and 2000 digital school course books, and the Ien YouTube channel has 750,000 subscribers for 5400 recorded lessons and 4000 live teaching hours [15].

Hitherto, distance learning in Saudi Arabia has consequently provided many educational courses and recorded lessons, which students can engage with at any time to advance their learning, without being restricted to a classroom or timetable. The current complete shift towards online learning has encouraged students to explore new technologies and learn new ways of obtaining information. Online learning has harnessed a wide range of 
educational styles based on Information Technology (IT), which helps students to interact in positive ways, resulting in the potential for massive innovation [16]. Nowadays, online learning enables parents to supervise their children's educational activities. Al-Mayman points out that 'Madrasati, a free educational platform which has been operating since August, will facilitate learners' evaluation and communication between teaching staff and students as well as their parents' [13]. Others adds that 'online learning diversifies learning strategies and contributes to the development of students' thinking skills through the use of technology that they love and use on a daily basis' $[13,14]$.

Conversely, despite acceptance among many Saudis, the culture of remote learning still presents a considerable challenge that must be addressed. There is major controversy surrounding online learning and its benefits for Saudi students. Some Saudis have the preconception that this kind of learning does not require any effort to succeed. They also protest that the means of supervising students during their tests are still weak [16]. Also, Ziaul Hoq points out that 'special attention needs to be given [to] matters related to plagiarism' [13]. Meanwhile, some students might think that as they are not in school, they can do what they want, and so it is no longer important to study. Barakat states that 'distance learning does not support the idea of direct communication between the teacher and the student which may result in making the student lazy in his/her learning process because he/she is not under the domination of the teacher and the school administration' [17]. In the same vein, other scholars have suggested that 'we may need to explore methods [that are incorporated] with online teaching to enhance students' engagement [18] (p. 995).

Further to the above, Moawad investigated the stress caused by online learning during the COVID-19 pandemic among Saudi university students, studying 2271 male and female students at King Saud University [19]. He observed that 514 students were extremely stressed and anxious at the sudden shift from traditional face-to-face classes to online classes. Bao affirms that the success of an online course largely depends on an 'elaborate lesson plan design, creative and interactive teaching materials such as audio and video content' [20]. Since teachers and students have faced several difficulties due to the sudden shift from traditional to online classes, creative and innovative teaching in online courses is more imperative at this time than ever before.

Nevertheless, during the period of the pandemic, universities and educational institutions in Saudi Arabia have proved their effectiveness in education provision, especially in university education. A study carried out at King Khalid University aimed to assess the satisfaction of academic staff with the suspension of traditional teaching, and the shift towards online education, revealing that $55.9 \%$ of the participants 'agreed' or 'strongly agreed' that the sudden shift to web-based education took place smoothly, and 57.6\% 'agreed' or 'strongly agreed' that giving lectures remotely was more flexible than delivering them face to face [21]. AlSalih points out that 'the MoE is working in cooperation with experts in international organizations to conduct an extensive validating assessment study on distance learning in universities and schools, during and after the pandemic [15]. Therefore, online learning is not just a temporary solution for this period. The Saudi Minister of Education, Dr. Hamad bin Mohammed Al Al-Sheikh has declared that online learning could eventually become a strategic choice for Saudi Arabia and not just an alternative in response to the coronavirus crisis [22].

\subsection{Engagement in an Online EFL Course}

Learner engagement is an important element to consider in the development of an effective course, especially with a view to enhancing learning outcomes [22,23]. Regarding Handelsman et al., identifying the level of learners' engagement is helpful for teachers when they work with individual students or are engaged in designing the classroom environment [6]. The above scholars state that there are already numerous studies examining engagement at 'macro-level', for example, the National Survey of Student Engagement (NSSE) at Indiana University, which examined whether the institution's program and practices were having the desired effect on the learners' activities, outcomes, and expe- 
rience. Handelsman et al. further add that ' $[\mathrm{t}]$ he NSSE focuses on active learning and other educational experiences but does not focus on individual courses; rather, it assesses students' overall perceptions' [6] (p. 184). On this basis, the above scholars constructed a scale for measuring what happens around and in class, since the teacher will have an immediate effect on learners' behavior and feelings in class. Thus, the above-mentioned study would suggest that students spend less time studying outside class. Regarding the current situation in Saudi Arabia, the need to examine learners' engagement in online classes was identified as urgent because it is a new phenomenon, marking a sudden change in education, in contrast to the education landscape before the COVID-19 pandemic [24].

The term 'engagement' has been addressed in different ways throughout the literature. This variation is due to the way in which engagement is viewed in specific contexts, as well as the way that it can be affected by and relates to the educational environment. For example, Bundick et al. included in their review that engagement can be affected by the interaction between primary elements in the classroom environment-the student, teacher, and content. They, therefore, proposed a conceptual framework using a previous model of classroom instruction and learning to conceptualize how student engagement could be promoted in the classroom [25]. The questionnaire used in the above study was derived from Diemer et al.'s [26] student engagement questionnaire. Thirty-five participants from two college-level Arabic language classes in a university in the south-west of the USA were involved. The data analysis showed that the students believed iPads had an important impact in their learning engagement, promoting active learning in the classroom and enhancing their achievement [25]. Al-Bogami and Elyas [27] studied the use of iPad and other handheld devices in in classrooms for EFL students' engagement. Their study endeavored to illumine the extent to which a selection of iPad applications, used as a pedagogical tool, augment young learners' engagement and learning in EFL environments. The data revealed, based on the statistical evidence, that learners exhibited highly positive attitudes toward the use of the apps in their EFL classes (reading and vocabulary) as they found the apps bolstering their level of engagement and learning compared to traditional teaching paradigms [27].

Furthermore, Handelsman et al. state that engagement is a multidimensional phenomenon, adding that most definitions include behavioral and affective components [6]. The above authors cite Skinner and colleagues' in defining engagement as 'children's initiation of action, effort, and persistence on schoolwork, as well as their ambient emotional states during learning activities [6] (p. 185). In light of these various factors, due to the recent technological advancement and the current pandemic, change has been forced in traditional education, especially in Saudi Arabia. In turn, the use of portable devices and an online environment may bring about change in an EFL learner's feelings and interaction with a course, hence, in his or her engagement with that course. Learners would therefore become more involved with the material and more encouraged to assume a role in their own learning. In particular, Handelsman et al.'s [6] division of engagement factors is drawn upon in this study to examine EFL learners' engagement in their English classes during the current pandemic in Saudi Arabia.

\section{Research Methodology}

\subsection{Study Design}

This research follows a quantitative research approach because it can give a broader view of the sample's perception of a topic, rather than specifying a limited number of participants [28]. The quantitative data was acquired through random sampling, whereby a questionnaire was sent to the target sample and each member of that sample was given the opportunity to participate [29]. For the quantitative data, the questionnaires were translated into Arabic for the learners. Moreover, one item was modified from 'Going to the professor during office hours to review assignments or tests or to ask questions', to 'Going to the teacher during her free hours to review assignments or tests or to ask questions', because the latter would be more comprehensible to the participants at their 
level of education. The translated items were then checked by a translation expert in the field. Before distribution, the researchers showed the survey to an expert and tested it with teachers who were part of the sample, in order to reveal any confusing items. Then, a pilot study was subsequently carried out, after which, the questionnaire was sent out to collect the data.

To test the reliability of the questionnaire, an internal consistency test was conducted using SPSS software for the whole scale, except for the demographic section. The Cronbach's alpha was found to be 0.913 (see Appendix D, Table A2), which is within the desired range [30]. Regarding the survey sample's responses to the tool, 50 respondents were involved in a pilot study. These respondents had similar characteristics to those of the study sample. It is evident from the data tabulated in (Appendix D, Table A1) that all items related to their corresponding dimension, at a level of significance of 0.01 . This result indicates the validity of the instrument's internal consistency. It also demonstrates that the items had a statistically significant correlation to the dimension to which they belonged.

For the main data collection and due to the restrictions, the survey was created electronically using Google Forms, and then sent to the teachers via multiple methods, for example, through the Head of Graduate Studies, who had access to the sample population's contact information. Snowballing techniques, as per Emerson [29], were also implemented, where the survey was sent to a teacher with the request to forward it to her colleagues, thus ensuring that the survey reached the entire intended sample population. Finally, the data was coded and analyzed with SPSS version 26 and Microsoft Office Excel to derive the descriptive data. Normally distributed quantitative variables were presented as means and standard deviations (SD), and qualitative variables were expressed as frequency and percentages. ANOVA was then conducted to explore the statistical significance of the learning engagement, and the learners' feelings about their experience of attending online English classes. Pearson's correlation was likewise applied to discover the significance of the association between quantitative variables, with a $p$-value of $<0.05$ being considered statistically significant. The study variables consisted of engagement (an independent variable) and the learners' feelings about their experience (the dependent variable).

Hence, this study was conducted to investigate a single existing case in an all-female High School in Jeddah, Saudi Arabia. Questionnaires were the main instrument used for the purpose of this study, since such a design would allow the phenomenon to be investigated in depth [31]. It would also enable a better understanding to be gained of an existing case, relating to the use of a special teaching and learning platform provided by the MoE: a platform known as 'Madrasati'.

In the current study, Handelsman et al.'s Student Course Engagement Questionnaire (SCEQ) was adopted [6]. This questionnaire was originally developed to measure engagement in specific college courses. In particular, the above authors sought to develop a reliable scale for measuring such engagement, which few researchers had previously attempted. This scale was included in the present study to measure engagement with a High School English language course (see Appendix C). Handelsman et al. [6] constructed the measure mainly for use at micro-level, concerning what happens in and immediately surrounding a class [6]. They explained that they were looking at engagement from this perspective because they believed it to be the level where the practitioner had most control. Thus, it was where most changes could be made. According to Ab Rahman et al. [32], no other existing scale evaluates learners' engagement on an individual course, rather than a whole program-as in the case of the National Survey of Student Engagement (NSSE). The SCEQ has been validated in several studies [33].

In their 23-item measure, Handelsman et al. [6] divided engagement into four factors. The measure demonstrated high internal consistency in their study, with a coefficient alpha of between 0.76 and 0.82 . The above authors labeled the first factor, 'Skills engagement' since it reflects student engagement through skills practice. Meanwhile, the second factor was labeled 'Emotional engagement', relating student engagement to emotional involvement with the class material. The third construct, 'Participation/interaction engagement', 
identifies learner engagement through classroom participation, as well as through interaction with instructors and peers. Finally, the fourth factor relates student engagement to performance in class, referred to as 'Performance engagement'.

Based on the outcomes of this case study, recommendations were drawn up to develop a current EFL online educational program. The study concentrated solely on measuring engagement among EFL learners in English classes, without looking at other courses. The researchers asked permission for access from the Saudi MoE, and this permission was granted. Several ethical considerations were addressed, such as obtaining approval from all the students before starting the research. Approval from the School Principal in Jeddah was also obtained. It was emphasized that all data would be kept confidential and would not be disclosed except for the purposes of this study.

\subsection{Study Population}

Between October and December 2020, all learners in the 68th High School for Girls in the city of Jeddah were invited through their English teachers to join the study. As mentioned earlier, an electronic questionnaire was subsequently distributed to all the female students at the 68th High School, and each participant was asked to sign the consent (see Appendix B). According to the characteristics presented in Table 1, below, 379 female students agreed to participate in the case study, comprising $96 \%$ of the study community.

Table 1. Characteristics of the participants $(n=379)$.

\begin{tabular}{|c|c|c|c|}
\hline & Categories & $\mathbf{N}$ & $\%$ \\
\hline \multirow{3}{*}{ School Grade } & Grade 10 & 123 & $32 \%$ \\
\hline & Grade 11 & 193 & $51 \%$ \\
\hline & Grade 12 & 63 & $17 \%$ \\
\hline \multirow{3}{*}{ Age } & $<15$ years & 25 & $7 \%$ \\
\hline & 16-17 years & 315 & $83 \%$ \\
\hline & $>17$ years & 39 & $10 \%$ \\
\hline \multirow{2}{*}{ City } & Jeddah & 379 & $100 \%$ \\
\hline & Other & - & - \\
\hline \multirow{3}{*}{ Gender } & Female & 379 & $100 \%$ \\
\hline & Male & - & - \\
\hline & Total & 379 & $100 \%$ \\
\hline
\end{tabular}

\section{Results}

To answer the first question, 'What is the level of engagement in English classes among High School EFL female learners when online learning is adopted?', it was found that engagement in English classes among female High School EFL learners, when online learning was adopted, was generally at a high level of 'Characteristic of me' (mean $=4.08, \mathrm{SD}=0.547$ ). Here, 'Performance engagement' was ranked first (mean $=4.53, \mathrm{SD}=0.542)$, indicated as 'Very characteristic of me'; 'Skills engagement' was ranked second (mean $=4.09, \mathrm{SD}=0.564$ ), indicated as 'Characteristic of me'; 'Emotional engagement' was ranked third (mean $=3.88$, $\mathrm{SD}=0.799)$, indicated as 'Characteristic of $\mathrm{me}^{\prime}$, and 'Participation/interaction engagement' was ranked fourth (mean $=3.81, \mathrm{SD}=0.713$ ), indicated as 'Characteristic of me'.

\subsection{Skills Engagement}

In Table 2, it can be observed that skills engagement in English classes among female High School EFL learners, when online learning was adopted, was generally at the level: 'Characteristic of me' (mean $=4.09, \mathrm{SD}=0.564)$ for the level of engagement. This illustrates that the learners had skills engagement in the EFL course they were receiving via an online environment. 
Table 2. Descriptive data for the students' skills engagement.

\begin{tabular}{cccccc}
\hline No. & Item & Mean & SD & Arrangement & Level of Engagement \\
\hline 1 & Making sure to study on a regular basis & 3.91 & 0.873 & 7 & Characteristic of me \\
\hline 2 & Exerting effort & 4.15 & 0.841 & 4 & Characteristic of me \\
\hline 3 & Doing all homework problems & 4.56 & 0.704 & 2 & $\begin{array}{c}\text { Moderately characteristic of } \\
\text { me }\end{array}$ \\
\hline 4 & Staying up to date with the readings & 3.38 & 1.100 & 9 & Characteristic of me \\
\hline 5 & $\begin{array}{c}\text { Looking over class notes between classes to } \\
\text { make sure I understand the material }\end{array}$ & 3.81 & 1.019 & 8 & Characteristic of me \\
\hline 6 & Being organized & 4.06 & 0.981 & 5 & Characteristic of me \\
\hline 8 & Taking good notes in class & 4.01 & 0.936 & 6 & Characteristic of me \\
\hline 9 & Listening carefully in class & 4.19 & 0.845 & 3 & Very characteristic of me \\
\hline & Coming to class every day & 4.77 & 0.503 & 1 & Characteristic of me \\
\hline
\end{tabular}

'Coming to class every day' was indicated as 'Very characteristic of me' and ranked first (mean $=4.77, \mathrm{SD}=0.503)$; 'Solving all homework problems' was likewise indicated as 'Very characteristic of me' and ranked second (mean $=4.56, \mathrm{SD}=0.704)$, while 'Staying up to date with the readings' was ranked third (mean $=3.38, \mathrm{SD}=1.100)$, indicated as 'Moderately characteristic of me'. The results indicate that the learners had skills engagement $($ mean $=4.09, \mathrm{SD}=0.564)$.

\subsection{Emotional Engagement}

In Table 3, it can be observed that the emotional engagement in English classes among female High School EFL learners, when online learning was adopted, was generally at the level: 'Characteristic of $\mathrm{me}^{\prime}$ (mean $=3.88, \mathrm{SD}=0.799$ ). As the results reveal, the learners were emotionally engaged in the classroom environment, since they responded positively to these elements in the scale, whereupon the scale indicated the participants' emotional engagement as emotional involvement with the class material. For example, 'Really desiring to learn the material' was ranked first (mean $=4.26, \mathrm{SD}=0.893$ ), with a level of engagement indicated as 'Very characteristic of me'. Meanwhile, 'Finding ways to make the course interesting for me' was ranked second (mean $=4.06, \mathrm{SD}=1.002$ ), with a level of engagement indicated as 'Characteristic of $\mathrm{me}^{\prime}$, and 'Thinking about the course between class meetings' was ranked third (mean $=3.13, \mathrm{SD}=1.275)$.

Table 3. Descriptive data for the students' emotional engagement.

\begin{tabular}{cccccc}
\hline No. & Items & Mean & SD & Arrangement & Level of Engagement \\
\hline 1 & $\begin{array}{c}\text { Finding ways to make the course material relevant to } \\
\text { my life }\end{array}$ & 4.02 & 1.034 & 3 & Characteristic of me \\
\hline 2 & Applying the course material to my life & 3.95 & 1.058 & 4 & Characteristic of me \\
\hline 3 & Finding ways to make the course interesting for me & 4.06 & 1.002 & 2 & Characteristic of me \\
\hline 4 & Thinking about the course between class meetings & 3.13 & 1.275 & 5 & Moderately characteristic of me \\
\hline 5 & Really desiring to learn the material & 4.26 & 0.893 & Very characteristic of me \\
\hline & Emotional engagement & 3.88 & 0.799 & Characteristic of me
\end{tabular}

\subsection{Participation/Interaction Engagement}

In Table 4, the participation/interaction engagement in English classes among female High School EFL learners, when online learning was adopted, was generally at the level: 'Characteristic of me' (mean $=3.81, \mathrm{SD}=0.713$ ). For example, the learners responded to the following points: 'Helping fellow students' was ranked first (mean $=4.25, \mathrm{SD}=0.838$ ), with a level of engagement indicated as 'Very characteristic of me'; 'Raising my hand in 
class' was ranked second (mean $=4.13, \mathrm{SD}=0.931$ ), with a level of engagement ranked as 'Characteristic of me', and 'Going to the teacher during her free hours to review assignments or tests or to ask questions' was ranked third (mean $=3.08, \mathrm{SD}=1.250$ ), with a level of engagement indicated as 'Moderately characteristic of $\mathrm{me}^{\prime}$. The results indicate that the learners had participation/interaction engagement (mean $=3.81, \mathrm{SD}=0.713$ ).

Table 4. Descriptive data for the students' participation/interaction engagement.

\begin{tabular}{|c|c|c|c|c|c|}
\hline No. & Items & Mean & SD & Arrangement & Level of Engagement \\
\hline 1 & Helping fellow students & 4.25 & 0.838 & 1 & Very characteristic of me \\
\hline 2 & Raising my hand in class & 4.13 & 0.931 & 2 & Characteristic of me \\
\hline 3 & Participating actively in small-group discussions & 3.99 & 0.947 & 3 & Characteristic of me \\
\hline 4 & Having fun in class & 3.92 & 0.991 & 4 & Characteristic of me \\
\hline 5 & $\begin{array}{c}\text { Asking questions when I don't understand } \\
\text { the instructor }\end{array}$ & 3.50 & 1.139 & 5 & Characteristic of me \\
\hline 6 & $\begin{array}{l}\text { Going to the teacher during her free hours to review } \\
\text { assignments or tests or to ask questions }\end{array}$ & 3.08 & 1.250 & 6 & Moderately characteristic of me \\
\hline & Participation/interaction engagement & 3.81 & 0.713 & & Characteristic of me \\
\hline
\end{tabular}

\subsection{Performance Engagement}

In Table 5, it may be seen that performance engagement in English classes among female high school EFL learners, when online learning was adopted, was generally at the level: 'Characteristic of me' (mean $=4.08, \mathrm{SD}=0.547$ ). It should be considered that one of the main aims of any educational program is to instill and foster a sense of needing to succeed on a course. The following statements elicited the most agreement from the learners: 'Doing well in the tests' was ranked first (mean $=4.58, \mathrm{SD}=0.635)$, with a level of engagement indicated as 'Very characteristic of me'; 'Getting a good grade' was ranked second (mean $=4.53, \mathrm{SD}=0.663$ ), with a level of engagement indicated as 'Very characteristic of $\mathrm{me}^{\prime}$, and 'Being confident that I can learn and do well in class' was ranked third (mean $=4.48, \mathrm{SD}=0.721$ ), with a level of engagement indicated as 'Very characteristic of me'. A correlation test was also conducted (see Appendix D, Table A3), where it may be observed that the correlation analysis revealed a relationship between all student engagement factors. The results indicate that the learners had a performance engagement $($ mean $=4.53, \mathrm{SD}=0.542)$.

Table 5. Descriptive data for the students' performance engagement.

\begin{tabular}{cccccc}
\hline No. & Items & Mean & SD & Arrangement & Level of Engagement \\
\hline 1 & Getting a good grade & 4.53 & 0.663 & 2 & 1 \\
2 & Doing well in tests & 4.58 & 0.635 & Very characteristic of me & Very characteristic of me \\
3 & Being confident I can learn and do well in class & 4.48 & 0.721 & Very characteristic of me & Very characteristic of me \\
& Performance engagement & 4.53 & 0.542 & & \\
\hline
\end{tabular}

To answer the second question, 'How do female EFL learners feel towards receiving instruction in English classes in an online environment?', it was found that $59 \%$ of the students were 'Satisfied' with their experience of attending English classes, 37\% were 'Somewhat satisfied', and just 4\% were 'Not satisfied' (see Table 6). More than half of the learners were positive about their experience of studying online, thereby indicating their engagement with the course. Further analysis was then conducted on these data. 
Table 6. Descriptive data for students' feelings about their online learning experience.

\begin{tabular}{cccc}
\hline Variables & Categories & N & \% \\
\hline \multirow{2}{*}{$\begin{array}{c}\text { How do you feel about } \\
\text { attending English } \\
\text { classes virtually? }\end{array}$} & Satisfied & 223 & $59 \%$ \\
\cline { 2 - 4 } & Somewhat Satisfied & 140 & $37 \%$ \\
\cline { 2 - 4 } & Not Satisfied & 16 & $4 \%$ \\
\hline
\end{tabular}

On conducting a one-way ANOVA test, it may be seen from Table 7 that there was a relationship between the learners' engagement and their feelings about their experience of attending online English classes $(p<0.01)$.

Table 7. Relationship between the learners' engagement and their feelings about their experience of attending online English classes.

\begin{tabular}{|c|c|c|c|c|c|c|}
\hline \multicolumn{2}{|c|}{ Variables } & \multirow{2}{*}{$\frac{\mathbf{N}}{16}$} & \multirow{2}{*}{$\begin{array}{c}\text { Mean } \\
3.8463\end{array}$} & \multirow{2}{*}{$\begin{array}{c}\text { SD } \\
0.47991\end{array}$} & \multirow[t]{2}{*}{$\mathbf{f}$} & \multirow[t]{2}{*}{$p$-Value * } \\
\hline \multirow{3}{*}{ Skills engagement } & Dissatisfied & & & & & \\
\hline & Somewhat satisfied & 140 & 3.8881 & 0.62211 & \multirow[t]{2}{*}{20.204} & \multirow[t]{2}{*}{0.01} \\
\hline & Satisfied & 223 & 4.2401 & 0.48107 & & \\
\hline \multirow{3}{*}{ Emotional engagement } & Dissatisfied & 16 & 3.6375 & 0.76322 & \multirow{3}{*}{9.864} & \multirow{3}{*}{0.01} \\
\hline & Somewhat satisfied & 140 & 3.6743 & 0.82735 & & \\
\hline & Satisfied & 223 & 4.0323 & 0.75172 & & \\
\hline \multirow{3}{*}{$\begin{array}{l}\text { Participation/interaction } \\
\text { engagement }\end{array}$} & Dissatisfied & 16 & 3.6044 & 0.67122 & \multirow{3}{*}{20.058} & \multirow{3}{*}{0.01} \\
\hline & Somewhat satisfied & 140 & 3.5396 & 0.71460 & & \\
\hline & Satisfied & 223 & 3.9950 & 0.65770 & & \\
\hline \multirow{3}{*}{ Performance engagement } & Dissatisfied & 16 & 4.5831 & 0.35586 & \multirow{3}{*}{8.484} & \multirow{3}{*}{0.01} \\
\hline & Somewhat satisfied & 140 & 4.3840 & 0.61389 & & \\
\hline & Satisfied & 223 & 4.6190 & 0.48397 & & \\
\hline
\end{tabular}

* One-way ANOVA.

Furthermore, an open-ended question was added to the questionnaire, with the potential to gain more understanding from the learners, as they would be able to give reasons for their satisfaction or dissatisfaction with their experience of learning in an online environment. Content analysis was used to organize the themes in the responses given [31]. By examining the valid responses, the frequency of certain themes was noted in the texts (see Tables 8 and 9).

Table 8. The responses given by the learners for being dissatisfied with their experience of learning English in an online learning environment.

\begin{tabular}{cccc}
\hline $\begin{array}{c}\text { Reasons for Not Being Satisfied with the } \\
\text { Online Environment }\end{array}$ & No. of Responses & $\%$ & Examples \\
\hline Problems in understanding & 6 & $46 \%$ & "Difficulties in understanding" \\
\hline Poor connection & 1 & $8 \%$ & $\begin{array}{c}\text { "Because sometimes, I have a bad connection and that } \\
\text { affects my learning" }\end{array}$ \\
\hline Pressures & 1 & $8 \%$ & $\begin{array}{l}\text { "I prefer to attend normal classes; I noticed difficulties in } \\
\text { my ability to learn, and pressures" }\end{array}$ \\
\hline Difficulties in concentration & 2 & $15 \%$ & $\begin{array}{c}\text { "I cannot concentrate ... too noisy ... I didn't get my } \\
\text { chance to participate" }\end{array}$ \\
\hline Lack of real interaction & 2 & $15 \%$ & "No real interaction" \\
\hline Accepting the online environment & 1 & $8 \%$ & "I don't like studying online" \\
\hline Total & 13 & $100 \%$ & \\
\hline
\end{tabular}


Table 9. Responses given for being satisfied with the experience of learning English in an online environment.

\begin{tabular}{|c|c|c|c|}
\hline $\begin{array}{l}\text { Reasons for Being Satisfied in the Online } \\
\text { Environment }\end{array}$ & $\begin{array}{l}\text { Numbers of } \\
\text { Responses }\end{array}$ & Percentage & Examples \\
\hline Easier to understand & 81 & $49.4 \%$ & $\begin{array}{l}\text { "The information is delivered in a simple way" } \\
\text { "Very satisfied, because I understand the } \\
\text { syllabus better" } \\
\text { "The teacher delivers the information simply } \\
\text { and clearly" }\end{array}$ \\
\hline The role of the teacher & 19 & $11.6 \%$ & $\begin{array}{l}\text { "I love the English language and my teacher helps us } \\
\text { to speak and work during class" } \\
\text { "The teacher is cooperative" }\end{array}$ \\
\hline Learning the language in the right way & 12 & $7.3 \%$ & "Enjoying learning the language in the right way" \\
\hline $\begin{array}{l}\text { Giving more opportunities for learners } \\
\text { to participate }\end{array}$ & 9 & $5.5 \%$ & "I can participate more and understand more" \\
\hline Multiple resources & 9 & $5.5 \%$ & The 'Ain' channel and WhatsApp \\
\hline Helping us to concentrate more & 6 & $3.7 \%$ & $\begin{array}{l}\text { "So, I have enough free time to learn how to read and } \\
\text { write in English" }\end{array}$ \\
\hline To limit the spread of the virus & 6 & $3.7 \%$ & $\begin{array}{l}\text { "Satisfied with the experience in helping to stop the } \\
\text { spread of the virus" }\end{array}$ \\
\hline Efficacy of the strategies used & 5 & $3.0 \%$ & "The strategies used, and the online teaching are nice" \\
\hline New experience & 5 & $3.0 \%$ & $\begin{array}{l}\text { "New method of education which suits my age and } \\
\text { mentality" } \\
\text { "Exciting and a good way to learn" }\end{array}$ \\
\hline Improving language skills & 3 & $1.8 \%$ & "Private lesson, feeling comfortable and safe" \\
\hline Independency in learning & 3 & $1.8 \%$ & "Being more independent in learning" \\
\hline Saving time and effort & 2 & $1.2 \%$ & "Online learning helped save me time and effort" \\
\hline $\begin{array}{c}\text { Reducing negative feelings (anxiety } \\
\text { and stress) }\end{array}$ & 2 & $1.2 \%$ & $\begin{array}{l}\text { "I am a shy person, and online learning gave me a } \\
\text { chance to participate and not be afraid of making } \\
\text { mistakes, and motivated me to answer" }\end{array}$ \\
\hline Using technology for description & 1 & $0.6 \%$ & $\begin{array}{l}\text { "Using technology to describe the content" } \\
\text { "I love technology" }\end{array}$ \\
\hline Using dictionary and translation & 1 & $0.6 \%$ & $\begin{array}{l}\text { "Learning and translation are easier because we are } \\
\text { using multiple means" }\end{array}$ \\
\hline Total & 164 & $100.0 \%$ & \\
\hline
\end{tabular}

It was found from the descriptive data provided by the respondents (see Appendix D, Table A4) that $72 \%$ of the students used the enrichments and links that were available on the Madrasati platform, relating to English as a school subject. Using an online environment helped the learners to be more independent in that they put the course material into practice and accessed the enrichments for themselves. Moreover, they indicated that the experience was beneficial, as they were able to participate more during class and avail themselves of multiple resources. The collected responses to this question indicate the various levels of learner engagement in a classroom environment, as defined by Handelsman et al. [6]. From these results, it can be seen that the learners displayed engagement in their online English classes. Due to their engagement, they described their experience as satisfactory.

\section{Discussion}

Based on the results presented in this paper, the sampled learners showed engagement with their online English classes in relation to several constructs of engagement with their course. Specifically, it was evident in the survey responses that the learners showed engagement through classroom participation; engagement through interaction with instructors and peers; engagement through skills practice; engagement through their emotional involvement with the class material, and engagement through their performance in class. In addition, a positive correlation was found between their satisfaction and engagement. Therefore, based on the learners' engagement, it was deduced that they were satisfied 
with receiving instruction via an online environment. Another study, conducted by Graham [34], tested the impact of social media on Humanities students at a British university, when learning outside the classroom. From the questionnaire results, it was found that the students' engagement with learning outside the classroom was enhanced by using social media for learning purposes. Similarly, Rose et. al found that by using videos with chemistry students, the learners showed engagement with the learning material outside the classroom and achieved better exam results [34]. In the same vein, Al-Bogami and Elyas study on EFL classes found the apps bolstering their level of engagement and learning compared to traditional teaching paradigms which helped to foster more active learning in the classroom [27]. From the results of this current and previous studies and by adopting a robust research approach, it could be claimed that using an online environment with other technological tools like videos and links could support learners' engagement both within and outside the classroom, whether emotionally or in terms of participation, skills and performance.

As mentioned previously, these findings indicate that a move toward online courses can be effective. They support that the different types of engagement considered in this study may be enhanced in various ways as a result of studying online, in comparison with traditional teaching. To elaborate on this, traditional teaching methods that have continuously hindered change $[3,35]$ were examined, even though it could be asserted that change is what the educational setting desperately needs. Traditional methods often give teachers immense control, which they exert over their students [36,37]. Consequently, students have not been given sufficient capacity to create or express themselves, with the result that they can be lacking in some areas at later stages of their learning. Moreover, given that online learning skills are necessary in modern educational environments, together with skills in academic writing and research (thereby promoting learners' development), practical training is essential [38].

However, many high school students appear to be barely acquainted with computers and academic writing, let alone versed in research methods. This introduces paradoxes into the university setting: what is expected in university settings contradicts what is cultivated in the schools. Classroom materials appeared to rely heavily on a teacher-delivery-teachercentered approach, whereby the students mainly received or were spoon-fed information $[39,40]$. On the implementation of e-learning, as indicated by the survey results, the learners felt satisfied because they found the approach to be suitable for their age group and mindset. Moreover, they found the course fun, and described their teacher as cooperative. Consequently, they were able to take control of their own learning, displaying skills engagement. To an even greater extent, the learners exhibited performance engagement, finding themselves able to learn and keen to succeed in their exams. Furthermore, they showed that they were using the available enrichments to help them study during their free time.

Another example of the shortcomings of traditional methods is the way that schools often emotionally inhibit students, where these students are not sufficiently exposed to emotional care in the school setting. Growing up with such assumptions could compromise their communicative abilities, as well as preventing trust from developing between students and teachers [40]. This could be a reason why some students are inactive in certain classes [41,42]; their emotions are continuously suppressed and their ability to express themselves might be ruptured. Schools have traditionally tended to focus primarily on providing information, while other human factors such as emotions have been neglected. These are some of the many issues originating in the nature of the traditional classroom. However, in this current study, online learning appeared to enhance the learning situation, as indicated in the survey results. The learners seemed to be more confident and motivated to participate, interacting with each other and with their teacher. They even offered to help their peers, as well as demonstrating they were trying to apply what they had learned in the classroom to their everyday lives, as displayed in their emotional engagement. 
However, in the circumstances created by COVID-19, another dimension has been introduced, in that traditional methods have simply become impossible to implement. Arguably, however, the physical medium that previously gave presence to the teacher and students, along with ways of enacting authority and control, was in any case gradually becoming obsolete [39]. The need for social distancing during the pandemic has further shifted the physical classroom environment to something different, remote. As a result, some of the control has been taken from one hand and placed in the other. Remote learning has brought to light the years of classroom imbalances now manifesting in conflict and alienation [38-40]. It has revealed how Saudi education was previously advancing very slowly in conceptual terms. This slow progress has been exhibited as incompatibility with the online medium. Consequently, teachers are struggling to cope with the change.

What has occurred in practice is that the teacher's role has been supplemented with appropriate changes to reflect general societal advancement. The spread of the COVID-19 pandemic has forced such change onto unfamiliar ground, but it is not COVID-19 itself that renders the ground unfamiliar; it is rather the actual role of the teacher that has been stuck in a loop for generations, neglecting the potential for necessary change [43]). This has left teachers incapacitated, struggling to cope with the new medium [39]. Whereas society itself has adopted different technologies and became acquainted with their use, education has heavily controlled how students receive information, and continue to impose traditional methods [39]. However, this contradicts the free nature of remote learning. As the results of this present study indicate, the learners showed to have participation/interaction engagement with their online learning. For example, timid learners felt more confident about interacting and expressing their thoughts freely. Furthermore, most of the learners found the experience to be fun and engaging.

Nevertheless, the medium of remote-learning places students and teachers on almost equal levels of control, which is where conflict and alienation can arise. Without a physical presence, students can deviate from classroom expectations; they may either oppose instructions or refuse to comply $[39,40,44,45]$. In the present study, the teacher's role included expectations of compliance that could not be enforced through the current medium, due to its virtual nature. This potentially creates a big gap for those who identify themselves with traditional teaching methods, but now find themselves suddenly having to use a medium that demands a different approach. Being without a suitable approach can alienate teachers by making them feel that their presence is no longer necessary [46]. As their role has hitherto been associated with a high level of control, the backlash could also be immense. Nevertheless, this previous control rendered the learning environment less than dynamic, which can be seen in the transition itself. Because the traditional classroom relies heavily on teachers' involvement, teachers have sometimes felt excluded by the new medium [39].

\section{Conclusions}

This study has demonstrated that a solution should not include either dispensing with the teacher or forcibly re-adopting traditional methods; instead, it should be more about relaxing the teacher's control, involving the students, and adjusting the new medium to suit the needs of both sides. The teacher's role consequently needs to change from being authoritative to being cooperative and engaging. In a cooperative classroom, teachers are part of an interactive environment that focuses on aural and visual stimulation [27]). The teacher's role here does not solely consist of presenting the material, but also of introducing students to creative new learning methods. Thus, students become creators, designers, and authors, independently shaping their own experiences, and actively contributing to the learning environment of a classroom. This, can be achieved through visual and aural guidance, while the teacher acts as a creative guide, enhancing the students' experiences through constructive feedback $[27,45]$.

In conclusion, a whole range of needs have called upon an imperative reform for educational change worldwide and in 'Saudi Arabia' [46,47]. However, to involve students in the new medium, it is essential to understand what they are already familiar with 
and why [48]. This will contribute towards the classroom a meaningful experience by transforming familiarity into something new and beneficial [48]. Given the abundant ways in which remote learning enables interaction, it is possible to create a dynamic environment that shapeshifts according to students' individual differences, reflected in the cooperative efforts of teachers and students [9]. We can argue that the sole benefit offered by COVID-19 is to highlight the usefulness and potential of this new method of teaching and learning, and its activation in the current education system worldwide. In any case, traditional learning has already been affected by the rapid global development of technology, which has especially impacted Saudi Arabia $[35,49]$. These abrupt changes in education are linked with teachers' teaching-related decisions that were influenced by factors that were related to the existence of digital tools as well as the ability to use them purposefully in the home settings of teachers and students [50]. Ultimately, we are left with an imperative need for better-designed programs that are suitable for online learning, not only in the current crisis, but for the near and distant future [51]. In fact, this move is needed globally, which may enable stakeholders to face such situations more specifically in consideration with language teaching and learning. Online and/or distance learning has become an urgent necessity for higher education institutions, imposed by the nature of emergency conditions in which we live [52]. We, trust that the learning process will never be the same, making learning more interactive, fun, and engaging than ever. Thus, educators need to welcome these new changes with open arms and open minds.

Based on the current research, the following procedure is recommended: 1. Statistical examination of the relationship between engagement and learning outcomes: due to the limited time available for conducting this study, and because of the COVID-19 quarantine conditions, it was not possible to examine the change in EFL learners' performance in this study, or to relate that change to their engagement, 2. Application of the study to male High School students as well: a limitation of this current study was its exclusively female sample, due to limited accessibility and the short time period available to the researchers for data collection, 3. Follow-up interviews conducted with the participants to gauge a more comprehensive understanding of their feelings: conducting more in-depth interviews using semi structured or open interviews could help gain a deeper understanding of the impact and reception of online education.

Author Contributions: Conceptualization, I.O. and T.E.; methodology I.O. and T.E.; software, I.O. and T.E.; validation, I.O. and T.E.; formal analysis, I.O. and T.E.; investigation, I.O. and T.E.; resources, I.O. and T.E.; data curation, I.O. and T.E.; writing-original draft preparation, I.O. and T.E.; writingreview and editing, I.O. and T.E.; visualization, I.O. and T.E.; supervision, I.O. and T.E.; project administration, I.O. and T.E.; funding acquisition, I.O. and T.E. Both authors have read and agreed to the published version of the manuscript.

Funding: This research received no external funding.

Institutional Review Board Statement: Not applicable.

Informed Consent Statement: Informed consent was obtained from all subjects involved in the study.

Data Availability Statement: The data presented in this study are available on request from the corresponding author. The data are not publicly available due to the policy of data security given by the Ministry of Education in KSA.

Conflicts of Interest: The authors declare no conflict of interest. 


\section{Appendix A}

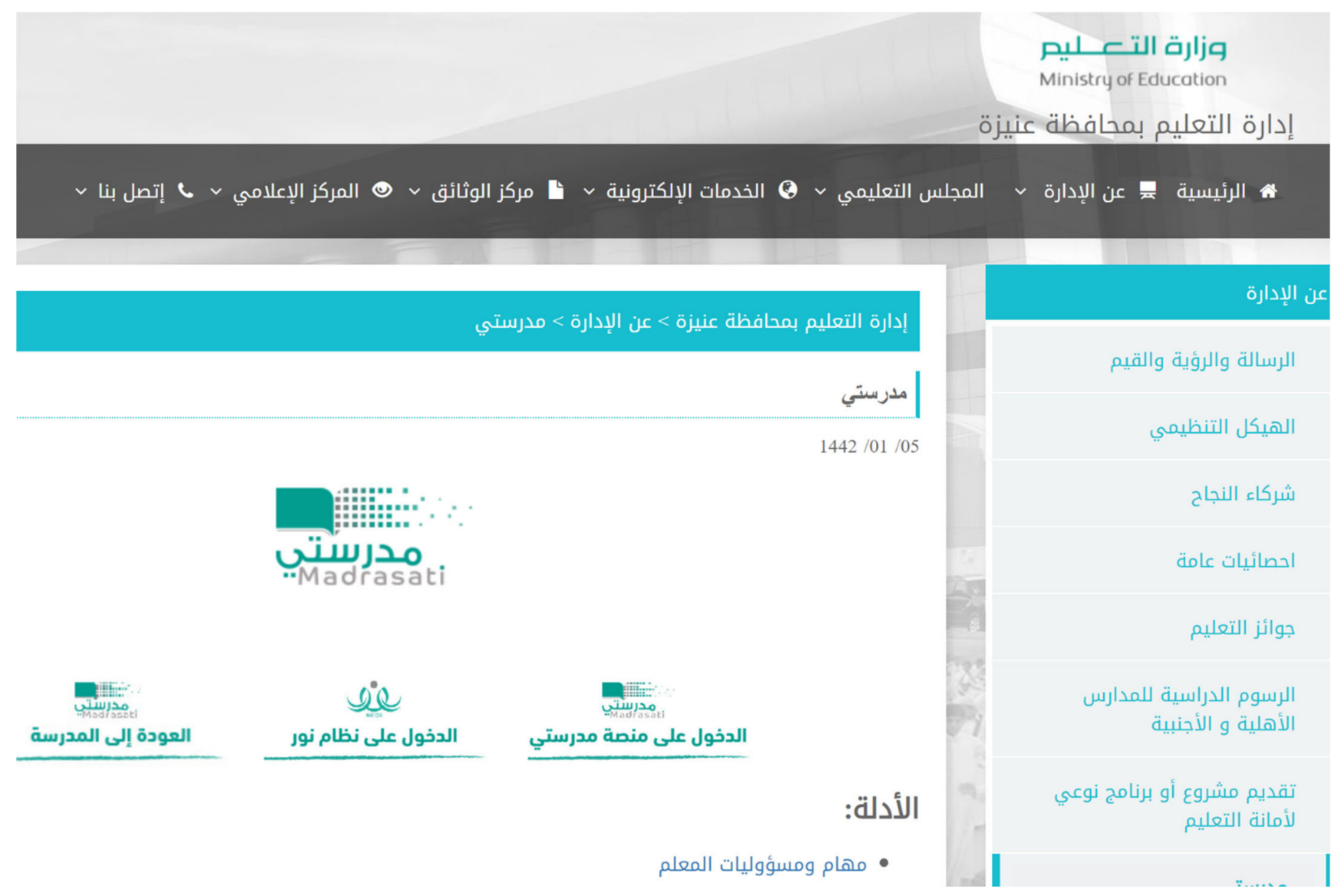

Figure A1. A screenshot of Madrasti in Saudi MoE.

\section{Appendix B}

Consent Form

You are kindly invited to participate in a short survey, consisting of this online questionnaire. It contains around 23 items and will not need more than $10 \mathrm{~min}$ to complete. The questionnaire is designed to discover your attitude to online learning and measure your engagement in online English classes. You have the right to withdraw from the survey at any stage. The data you provide will only be used for the purpose of this research and will not affect your grades. Every effort will be made to ensure the confidentiality of the collected data.

Your consent to participate in this survey will be greatly appreciated, making an essential contribution to my research.

Thank you for your cooperation.

Yours sincerely,

For further details, please feel free to contact the researchers, at any time on:

Email: e.oraif@gmail.com

Statement of consent:

I hereby agree to take part in this survey. I understand that the data will be protected and sign accordingly,

Participant's signature

Agree Do not agree 


\section{Appendix C}

Questionnaire

Part 1:

1. Year in school: Year 10 Year 11 Year 12

2. Age: Less than 15 years $16-17$ Years More than 18 Years

3. City ..............

4. Gender: Female Male

5. Do you use the enrichments and links available for the English subject on the 'Madrasti' platform?

Yes No

If your answer is No, please specify

6. If yes, do you rely solely on these enrichments and links to develop your English language skills?

Yes No

If your answer is No, please specify ..............

7. How do you feel about attending English language classes through the online environment?

Satisfied Somewhat satisfied Dissatisfied

Kindly, add your reasons ................

Part 2:

A. To what extent do the following statements describe your behavior and feelings while studying online for your English course? On the scale provided, please select the statement that best describes your feelings and behavior:

$5=$ Very characteristic of me

$4=$ Characteristic of me

$3=$ Moderately characteristic of me

$2=$ Not really characteristic of me

$1=$ Not at all characteristic of me

1. $\quad \ldots \ldots \ldots$...........ing sure to study on a regular basis

2. $\quad \ldots \ldots \ldots \ldots$. Putting forth effort

3. $\quad \ldots \ldots \ldots \ldots$. Doing all the homework problems

4. $\quad \ldots \ldots \ldots$. Staying up on the readings

5. ........... Looking over class notes between classes to make sure I understand the material

6. $\quad \ldots \ldots \ldots \ldots$. Being organized

7. $\quad \ldots \ldots \ldots \ldots$ Taking good notes in class

8. $\quad \ldots \ldots \ldots$. Listening carefully in class

9. $\quad \ldots \ldots \ldots$. Coming to class every day

10. $\ldots \ldots \ldots \ldots$ Finding ways to make the course material relevant to my life

11. .......... Applying course material to my life

12. $\ldots \ldots \ldots$. Finding ways to make the course interesting to me

13. $\ldots \ldots \ldots$ Thinking about the course between class meetings

14. $\ldots \ldots \ldots$. Really desiring to learn the material

15. ........ Raising my hand in class

16. .........Asking questions when I don't understand the instructor

17. $\ldots \ldots \ldots$. Having fun in class

18. $\ldots \ldots \ldots$. Participating actively in small group discussions

19. ......... Going to the teacher during her free hours to review assignments or tests, or to ask questions

20. $\quad \ldots \ldots \ldots$. Helping fellow students

21. .......... Getting a good grade

22. $\ldots \ldots \ldots$. Doing well in the tests

23. .........Being confident that I can learn and do well in class 


\section{Appendix D}

Table A1. Pearson's correlation coefficient between the item and the factor to which it belongs.

\begin{tabular}{|c|c|c|c|c|c|c|c|}
\hline \multicolumn{2}{|c|}{$\begin{array}{c}\text { Skills } \\
\text { Engagement }\end{array}$} & \multicolumn{2}{|c|}{$\begin{array}{c}\text { Emotional } \\
\text { Engagement }\end{array}$} & \multicolumn{2}{|c|}{$\begin{array}{c}\text { Participation/Interaction } \\
\text { Engagement }\end{array}$} & \multicolumn{2}{|c|}{$\begin{array}{l}\text { Performance } \\
\text { Engagement }\end{array}$} \\
\hline No. & $\mathrm{R}$ & No. & $\mathrm{R}$ & No. & $\mathrm{R}$ & No. & $\mathrm{R}$ \\
\hline 1 & $0.759 * *$ & 10 & $0.857^{* *}$ & 15 & $0.595^{* *}$ & 21 & $0.785^{* *}$ \\
\hline 2 & $0.765^{* *}$ & 11 & $0.761^{* *}$ & 16 & $0.773^{* *}$ & 22 & $0.849^{* *}$ \\
\hline 3 & $0.626^{* *}$ & 12 & $0.816^{* *}$ & 17 & $0.661 * *$ & 23 & 0.760 ** \\
\hline 4 & $0.671^{* *}$ & 13 & 0.761 ** & 18 & $0.600 * *$ & & \\
\hline 5 & $0.868^{* *}$ & 14 & $0.744^{* *}$ & 19 & $0.567^{* *}$ & & \\
\hline 6 & $0.673^{* *}$ & & & 20 & $0.502^{* *}$ & & \\
\hline 7 & $0.736^{* *}$ & & & & & & \\
\hline 8 & $0.625^{* *}$ & & & & & & \\
\hline 9 & $0.364^{* *}$ & & & & & & \\
\hline
\end{tabular}

${ }^{* *}$ Correlation is significant at the 0.01 level (2-tailed).

Table A2. Cronbach's alpha.

\begin{tabular}{ccc}
\hline Factors & No. of Items & \\
\hline Skills engagement & 9 & 0.860 \\
Emotional engagement & 5 & 0.830 \\
Participation/interaction engagement & 6 & 0.673 \\
Performance engagement & 3 & 0.710 \\
Overall & 23 & 0.913 \\
\hline
\end{tabular}

Table A3. Correlations and descriptive data for the student engagement factors.

\begin{tabular}{|c|c|c|c|c|c|c|}
\hline Factors & Mean & SD & $\begin{array}{c}\text { Skills } \\
\text { Engagement }\end{array}$ & $\begin{array}{c}\text { Emotional } \\
\text { Engagement }\end{array}$ & $\begin{array}{c}\text { Participation/Interaction } \\
\text { Engagement }\end{array}$ & $\begin{array}{l}\text { Performance } \\
\text { Engagement }\end{array}$ \\
\hline Skills engagement & 4.09 & 0.564 & & $0.584 * *$ & $0.728 * *$ & $0.580 * *$ \\
\hline $\begin{array}{c}\text { Emotional } \\
\text { engagement }\end{array}$ & 3.88 & 0.799 & & & $0.595^{* *}$ & $0.544 * *$ \\
\hline $\begin{array}{l}\text { Participation/interaction } \\
\text { engagement }\end{array}$ & 3.81 & 0.713 & $0.728 * *$ & $0.595 * *$ & & $0.531 * *$ \\
\hline $\begin{array}{l}\text { Performance } \\
\text { engagement }\end{array}$ & 4.53 & 0.542 & $0.580 * *$ & $0.544^{* *}$ & $0.531 * *$ & \\
\hline Overall & 4.08 & 0.547 & $0.860 * *$ & 0.830 ** & $0.673 * *$ & 0.710 ** \\
\hline
\end{tabular}

** Correlation is significant at the 0.01 level (2-tailed).

Table A4. Descriptive data for the resources used by students on the online platform.

\begin{tabular}{cccc}
\hline Variables & Categories & N & $\%$ \\
\hline \multirow{2}{*}{$\begin{array}{c}\text { Do you use the enrichments and links available for the English subject } \\
\text { on the 'Madrasti' platform }\end{array}$} & YES & 274 & $72 \%$ \\
\cline { 2 - 4 } & NO & 105 & $28 \%$ \\
\hline
\end{tabular}

\section{References}

1. Rahman, R.A.; Ahmad, S.; Hashim, U.R. A study on gamification for higher education students' engagement towards education 4.0. In Intelligent and Interactive Computing; Piuri, V., Balas, V.E., Borah, S., Syed Ahmad, S.S., Eds.; Springer: Singapore, 2019; pp. 491-502.

2. Affouneh, S.; Salha, S.N.; Khlaif, Z. Designing Quality E-Learning Environments for Emergency Remote Teaching in Coronavirus Crisis. Interdiscip. J. Virtual Learn. Med. Sci. 2020, 11, 1-3.

3. Al Arabiya (English). Distance Learning amid Coronavirus to Help School Dropouts in Saudi Arabia. Al Arabiya News. 2020. Available online: https:/ / english.alarabiya.net/en/coronavirus/2020/05/15/ (accessed on 26 July 2020). 
4. Al-Bogami, B.; Elyas, T. Promoting Middle School Students' Engagement through Incorporating iPad Apps in EFL/ESL Classes. SAGE Open 2020, 10. [CrossRef]

5. Al-Mayman, H. Saudi E-Learning Portal Ushers in New Normal with Virtual Classrooms. 512 Arab News. Available online: https:/ / www.arabnews.com/node/1730541/saudi-arabia (accessed on 6 September 2020).

6. Al-Sheikh, H. Online Learning after CORONA for the Better. Al Arabiya. Available online: https://www.alarabiya.net/ar/sauditoday /2020/04/20/ (accessed on 22 October 2020).

7. Alamer, O. The Culture of Distance Learning. Al-Jazirah Newspaper. Available online: https://www.al-jazirah.com/2020/20200 324/ar3.htm (accessed on 24 March 2020).

8. Aldwaihi, A. Available online: https://www.okaz.com.sa/articles/authors/2034871 (accessed on 26 July 2020).

9. Alfifi, A. After Coronavirus: Our Education towards the Best. Alriyadh Newspaper. Available online: http://www.alriyadh. com/1816856 (accessed on 20 April 2020).

10. AlHamid, S. Distance Learning. Okaz Newspaper. Available online: https://www.okaz.com.sa/articles/people-voice/2034184 (accessed on 23 July 2020).

11. Almaghaslah, D.; Alsayari, A. The Effects of the 2019 Novel Coronavirus Disease (COVID-19) Outbreak on Academic Staff Members: A Case Study of a Pharmacy School in Saudi Arabia. Health Policy Politi Sante 2020, 13, 795-802. [CrossRef]

12. AlSalih, K. Saudi Study for Assessment of Remote Learning Process. Alwatan Newspaper. Available online: https://www. alwatan.com.sa/article/1048932 (accessed on 20 June 2020).

13. AlShehri, Y.A.; Mordhah, N.; Alsibiani, S.; Alsobhi, S.; Alnazzawi, N. How the Regular Teaching Converted to Fully Online Teaching in Saudi Arabia during the Coronavirus COVID-19. Creat. Educ. 2020, 11, 985-996. [CrossRef]

14. Annetta, L.A.; Minogue, J.; Holmes, S.Y.; Cheng, M.-T. Investigating the impact of video games on high school students' engagement and learning about genetics. Comput. Educ. 2009, 53, 74-85. [CrossRef]

15. Barakat, R. Extension of Distance Learning in Saudi Arabia. Mhtwyat. Available online: https://bit.ly/35gxtPG (accessed on 11 August 2020).

16. Barata, G.; Gama, S.; Jorge, J.; Goncalves, D. Engaging Engineering Students with Gamification. In Proceedings of the 2013 5th International Conference on Games and Virtual Worlds for Serious Applications (VS-GAMES), Piscataway, NJ, USA, 11-13 September 2013.

17. Basalamah, O.; Elyas, T. Conceptualizing the virtual learning space(s) in Saudi Arabia: A Foucauldian panoptic approach. Int. J. Engl. Lang. Teach. 2014, 2, 1-15.

18. Basalamah, O.; Elyas, T. Conceptualizing virtual learning space(s) in Saudi Arabia: A Foucauldian panoptic approach. In Beyond the Postmodern: Reconceptualization of Space and Place for the Early 21st Century; Brelow, H., Ziethen, A., Eds.; Inter-Disciplinary Press: Oxford, UK, 2015; pp. 63-78. ISBN 978-1-84888-319-2.

19. Bao, W. COVID-19 and online teaching in higher education: A case study of Peking University. Hum. Behav. Emerg. Technol. 2020, 2, 113-115. [CrossRef]

20. Black, T.R. Doing Quantitative Research in the Social Sciences: An Integrated Approach to Research Design, Measurement and Statistics; Sage: Thousand Oaks, CA, USA, 1998.

21. Bundick, M.J.; Quaglia, R.J.; Corso, M.J.; Haywood, D.E. Promoting Student Engagement in the Classroom. Available online: http: / / www.tcrecord.org (accessed on 26 July 2014).

22. Cujba, S. How to Engage Students in Learning? Racoon Gang. Available online: https://raccoongang.com/blog/how-engagestudents-learning/ (accessed on 26 July 2017).

23. Diemer, T.T.; Fernandez, E.; Streepey, J.W. Student perceptions of classroom engagement and learning using iPads. J. Teach. Learn Technol. 2012, 1, 13-25.

24. Dörnyei, Z. Research Methods in Applied Linguistics: Quantitative, Qualitative, and Mixed Methodologies; Oxford University Press: Oxford, UK, 2007.

25. Elyas, T. Exploring the Challenges and Solutions of Web-Based Education on the Learners' Experiences during COVID-19 Pandemic: A Cognitive Psychological Approach. In Proceedings of the ASIA TEFL 2020 Conference, Goyang City, Korea, 13-15 July 2020.

26. Elyas, T. The Rise of Remote (Neo)Pedagogy in the Time of 21st Pandemic Era: Juxtaposing between Panoptic and Cognitive Approach in the Learners' Experiences. In Applied Linguistics \& Language Teaching (ALLT); Zayd University: Zayd, United Arab Emirats, 2020.

27. Emerson, R.W. Convenience Sampling, Random Sampling, and Snowball Sampling: How Does Sampling Affect the Validity of Research? J. Vis. Impair. Blind. 2015, 109, 164-168. [CrossRef]

28. González, M.A.; Santos, B.S.N.; Vargas, A.R.; Martín-Gutiérrez, J.; Orihuela, A.R. Virtual Worlds. Opportunities and Challenges in the 21st Century. Procedia Comput. Sci. 2013, 25, 330-337. [CrossRef]

29. Graham, M. Social Media as a tool for increased student participation and engagement outside the classroom in Higher Education. J. Perspect. Appl. Acad. Pr. 2014, 2, 16. [CrossRef]

30. Hamdan, M. حر الك المؤتمرات العلمية الطالبي. Saudi Opinions. Available online: https://www.saudiopinions.org/ar/30987/ (accessed on 29 August 2020).

31. Handelsman, M.M.; Briggs, W.L.; Sullivan, N.; Towler, A. A Measure of College Student Course Engagement. J. Educ. Res. 2005, 98, 184-192. [CrossRef] 
32. Heflin, H.; Shewmaker, J.; Nguyen, J. Impact of mobile technology on student attitudes, engagement, and learning. Comput. Educ. 2017, 107, 91-99. [CrossRef]

33. Jézégou, A. The influence of the openness of an e-learning situation on adult students' self-regulation. Int. Rev. Res. Open Distrib. Learn. 2013, 14, 182-201. [CrossRef]

34. Kantar. COVID-19 Barometer: Consumer Attitudes, Media Habits and Expectations. Available online: https://www.kantar.com/ Inspiration/Coronavirus/COVID-19-Barometer-Consumer-attitudesmedia-habits-and-expectations (accessed on 26 July 2020).

35. Khalid, T. Distance Learning amid Coronavirus to Help School Dropouts in Saudi Arabia: Minister. Al Arabiya (English). Available online: https://english.alarabiya.net/en/coronavirus/2020/05/15/Distance-learning-amid-coronavirus-to-helpschool-dropouts-in-Saudi-Arabia-Minister (accessed on 14 May 2020).

36. Lalani, F.; Li, C. The COVID-19 has Changed Education Forever. This is How. World Economic Forum. Available online: https:/ / www.weforum.org/agenda/2020/04/coronavirus-education-global-covid19-online-digital-learning/ (accessed on 29 April 2020).

37. Mahboob, A.; Elyas, T. English in the Kingdom of Saudi Arabia. World Engl. 2014, 33, 128-142. [CrossRef]

38. Lepp, L.; Aaviku, T.; Leijen, Ä.; Pedaste, M.; Saks, K. Teaching during COVID-19: The Decisions Made in Teaching. Educ. Sci. 2021, 11, 47. [CrossRef]

39. Lassoued, Z.; Alhendawi, M.; Bashitialshaaer, R. An Exploratory Study of the Obstacles for Achieving Quality in Distance Learning during the COVID-19 Pandemic. Educ. Sci. 2020, 10, 232. [CrossRef]

40. Mann, S.J. Alienation in the learning environment: A failure of community? Stud. High. Educ. 2005, 30, 43-55. [CrossRef]

41. McNamee, D. What are the Adult Health Consequences of Childhood Bullying? Medical News Today. Available online: https: / / www.medicalnewstoday.com/articles/283042 (accessed on 25 September 2014).

42. Moawad, R.A. Online Learning during the COVID-19 Pandemic and Academic Stress in University Students. Rev. Rom. Pentru Educ. Multidimens. 2020, 12, 100-107. [CrossRef]

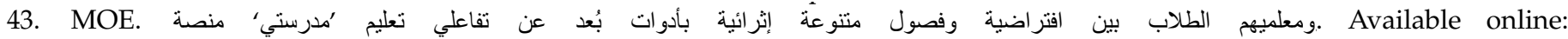
https:/ / www.moe.gov.sa/ar/news/pages/mn-2020-876.aspx (accessed on 26 July 2020).

44. Montague, B. Needing Change, Changing Needs. The Ecologist. Available online: https://theecologist.org/2019/apr/03 / needing-change-changing-needs (accessed on 26 July 2019).

45. Naar, I. Saudi Arabia Coronavirus: Distance Learning for First 7 Weeks of New Academic Year. Al Arabiya (English). Available online: https:/ / english.alarabiya.net/en/coronavirus/2020/08/15/Saudi-Arabia-Distance-learning-for-first-7-weeks-of-newacademic-year-amid-COVID-19 (accessed on 15 August 2020).

46. Nasir, M.A.M.; Janikowski, T.; Guyker, W.; Wang, C.C. Modifying the Student Course Engagement Questionnaire for use with online courses. J. Educ. Online 2020, 17, n1.

47. Obaid, R. Saudi Students, Educators take on Virtual Education Challenge Amid Coronavirus Suspension. Arab News. Available online: https: / / www.arabnews.pk/node/1640211/saudi-arabia (accessed on 26 July 2020).

48. Rose, J.; Pennington, R.; Behmke, D.; Kerven, D.; Lutz, R.; Paredes, J.E.B. Maximizing Student Engagement Outside the Classroom with Organic Synthesis Videos. J. Chem. Educ. 2019, 96, 2632-2637. [CrossRef]

49. Saati, A. Distance Learning and Coronavirus Crisis. Aleqt. Available online: https://www.aleqt.com/2020/04/05/article_179757 6.html (accessed on 5 April 2020).

50. Shereen, M.A.; Khan, S.; Kazmi, A.; Bashir, N.; Siddique, R. COVID-19 infection: Origin, transmission, and characteristics of human coronaviruses. J. Adv. Res. 2020, 24, 91-98. [CrossRef] [PubMed]

51. Skinner, E.A.; Wellborn, J.G.; Connell, J.P. What it takes to do well in school and whether I've got it: A process model of perceived control and children's engagement and achievement in school. J. Educ. Psychol. 1990, 82, 22-32. [CrossRef]

52. Thomas, G. How to Do Your Research Project: A Guide for Students; Sage: Thousand Oaks, CA, USA, 2017. 